\title{
Analysis of Engineer Obstacle Negotiation Possibility with Grouping Robots
}

\author{
Marian Janusz LOPATKA
}

Military University of Technology, Institute of Mechanical Engineering, ${ }^{2}$ gen. Witolda Urbanowicza Street, 00-908, Poland

E-mail: marian.lopatka@wat.edu.pl

\begin{abstract}
This paper the contain description of possibility of future combat engineer task robotization. The analysis is focused on most dangerous task like engineer obstacle breaching including mine fields, fence and other barriers. In the paper are described proposals of new technics and tactics for using robots and demand for their new possibilities
\end{abstract}

KEY WORDS: combat engineer robot, mine field, engineer obstacle crossing, robot team

\section{Introduction}

Overcoming the engineering obstacles is an extremely difficult, complex and dangerous task, because the barriers are assumed to be protected (defended) by enemy fire and they consist of a variety of obstacles including:

- minefield barriers;

- wire obstacles, fences, picket holdfasts, steel hedgehogs, concrete blocks, etc.;

- ground fortification barriers - antitank ditches, sidehill cuts, embankments and flooding.

Their breaching and clearance them requires ability to: making the lines in minefields by the explosive method; minesweeping; marking them; making lines in embankments and crossing ditches.

Combat engineer equipment. Because of the opponent's influence to making lines there are normally used manned, heavily armored tracked vehicles equipped with different attachments, tools and kits. The most popular are:

- mine-clearing line charge;

- mine plough, mine clearing rollers, flails;

- manipulators and excavator attachments;

- dozer and loader attachments;

- assault bridges.

Usually attachments and tools are grouped together creating specialized vehicles built on the basis of MBT (Main Battle Tank). Most commonly mine ploughs are grouped with mine-clearing line charge forming overcome mine barriers vehicles (mine-clearing vehicles) while manipulators and dozer or loader attachments create the vehicles making lines in other barriers.

Making line in extensive engineering obstacles therefore requires: mine-clearing vehicle, breaching vehicle, earthmoving vehicle and assault bridge vehicle. The weight and the size of these vehicles is dictated by the need of the crew protection and it is not necessary for most of these tasks from point of view demanded capabilities and their stability. However large weight and dimensions limit their agility and mobility. Introduction of the remotely controlled combat engineer robots allows to reduce their weight, improve terrain mobility and also reduce the risk for crews $[2,3,6]$.

Due to the impact of the opponent, manned - heavy, heavily armored tracked vehicles equipped with various attachments, tools and kits tools are used as standard. The most popular are:

- long devices - carried directly on armored vehicles or on towed trailers - they are used for explosive destruction of mines and dams with the use of explosive material with a length of 100-170 m moved to the minefield by means of rocket engines, their disadvantage is insufficient length in the case of erratic fields is too small width of the passage which in the case of mines with compensation of the pressure wave is at the level of $2 \mathrm{~m}$ and the lack of the possibility of precise extension or lengthening the passage by means of subsequent devices (no flight control of the rocket);

- mine clearing plow- expanding the passage made by the explosive method - depending on the ground conditions, the following can be used:

- excavations (sandy and loamy soils) - older solutions are rutting plows, but nowadays they with full trawling width are becoming more and more popular - they allow to make passes by removing layers of land from mines without causing detonation - with a speed of 5-6 km / H

- $\quad$ pressure (all types of land including stony and overgrown with perennial vegetation) - usually rutted - allow to pass at speeds of up to $8-10 \mathrm{~km} / \mathrm{h}$, which shortens the exposure of the crew, but causes detonations of trawled mines; 
- flail (recommended for sandy and loamy soils) - they traverse full-width passages - however, the trailing speed of $0.4 \mathrm{~km} / \mathrm{h}$ (maximum $1 \mathrm{~km} / \mathrm{h}$ ) limits their operational use;

- manipulators with a lifting capacity of approx. $2000 \mathrm{~kg}$ - used for fencing works - are usually equipped with grippers or bucket shovels with additional jaws for gripping - they also enable laying of fauns for backfilling of antitank ditches;

- bulldozer blades or buckets - used for fencing works and making passes in earth dams, in particular in earth gelding and ditches.

In order to overcome ditches, attack bridges are used to overcome narrow aqueous obstacles, however, their standard span of 20-25 m, does not correspond best to the needs related to crossing trenches with a width of approx. $5 \mathrm{~m}-$ hence the span structures of length 7-8 m, which are much lighter and easier to handle.

Usually attachments and tools are grouping to create specialized vehicles built on the basis of MBT (Main Battle Tank). Most often, the trawls are grouped with longitudinal devices, creating wagons for overcoming mining dams (trailing vehicles), while manipulators and attachments, bulldozers or loaders, create vehicles paving the passages in the remaining dams. Some of the combat engineer vehicles are additionally equipped with means for throwing loads, used to destroy dams and fortifications.

In the engineering dam's fortification objects are also used, such as antitank ditches or earth embankments. To overcome them the assault bridges carried on heavy tracked vehicles and pioneering vehicles equipped with plowshares are used. The efficiency of using pioneering vehicles built on the basis of MBT tanks for making passages in embankments or for backfilling of trenches is usually low because they are usually equipped (due to the visibility and angle of the driveway) with 2.5-3 m3 shares. As a result, despite of the mass of 45-60 thousand kg they have working capacity similar to track dozers weighing only 15 thousand $\mathrm{kg}$. For these reasons, to ensure high efficiency of earthworks, it is necessary to use heavy armored fortification machines.

Execution of the passage in extended engineering dams therefore requires the use of a trawler vehicle, a pioneering vehicle, a fortification machine and an assault bridge. The weight and size of these vehicles is dictated by the need to protect the crew and is not necessary for most of these tasks. Large weight and dimensions, however, limit their maneuverability and mobility. Eliminating crews will allow tasks to be carried out by smaller, more mobile robots and increase the security of their implementation.

\section{Problems and Limitations of Robotization.}

The limitation of robotization mainly depends from the current level of technology development [1,4,5,7]. Contemporary robots can successfully carry out repetitive activities - however they are not capable of autonomous actions requiring the robot to acquire new information, their analyses and decision making. These processes require the development of artificial intelligence. Currently used robots in order to fulfill unique tasks, requiring decision making must be controlled by man. If they work in direct operation's environment it is a sufficient solution to use remote control - the operator directly assesses the environment and controls all movements or its sequences. In case of operation at the greater distance or the occurrence of danger to the operator - the teleoperation is used. This means that the operator makes decisions and controls the robot based on the image obtained from the robot cameras. The remote control, especially teleoperation limited the operator's perceptual abilities in the area and of robot environment and location assessment and its working movements due to:

- delays occurring in the transmission path of the control signals;

- delays in image path of the robot's surroundings;

- limited viewing angle of the teleoperation system cameras;

- usually lack of stereovision - allowing quick distance assessment;

- too low image resolution due to the limited bandwidth output;

- no fillings of longitudinal and lateral inclinations of the robot and accelerations acting on the robot;

- no fillings contact between the robot and the ground;

- no fillings of vibrations and noise - allowing to assess the condition and load of the robot.

Limiting barriers requires the development of tele-presence technology. In addition, the relatively small teleoperation range of ground platforms, which currently does not exceed 1-1.5 km (due to the need for image transmission with delays not exceeding 0.1-0.2 seconds) limits both the scope and methods of task implementation (however, it is sufficient to carry out paving tasks).

Teleoperation creates new opportunities to carry out tasks. Lack of direct threat to the operator enables the use of new, different technologies, techniques and tools - the use of which is not expected in the case of vehicles and manned machines. Hence the design, applied solutions, mass and size of robots can differ significantly from manned platforms. They can also perform tasks in teams that complement each other's capabilities. As a result, eliminating a person from the immediate danger zone allows not only to reduce the risks, but also to increase the effectiveness of tasks in the danger zones, provided that the techniques and technologies for their implementation are changed.

\section{Possibilities of Making Transitions in Engineering Dams using Robots}

Analysis of tasks and tools necessary to perform passages in engineering dams indicates that most works can perform robots much smaller and lighter than manned platforms, because they do not require very large lifting forces and pull 
(large mass of manned vehicles results mainly from the need to provide space and protection for soldiers).

An example of this can be the basic task when making passes in dams - moving long loads along the foreground and making explosive passes. This task can be carried out by robots weighing only 5-6 thousand. kg (Fig. 1) able to carry long devices, the weight of which does not usually exceed 2 thousand. $\mathrm{kg}$. They can also, thanks to special mechanisms, remove the springs or tensioning cables remaining after detonation - Fig. 2 - reducing the risk of accidental blocking of the running gear and stopping vehicles when crossing the passage made.

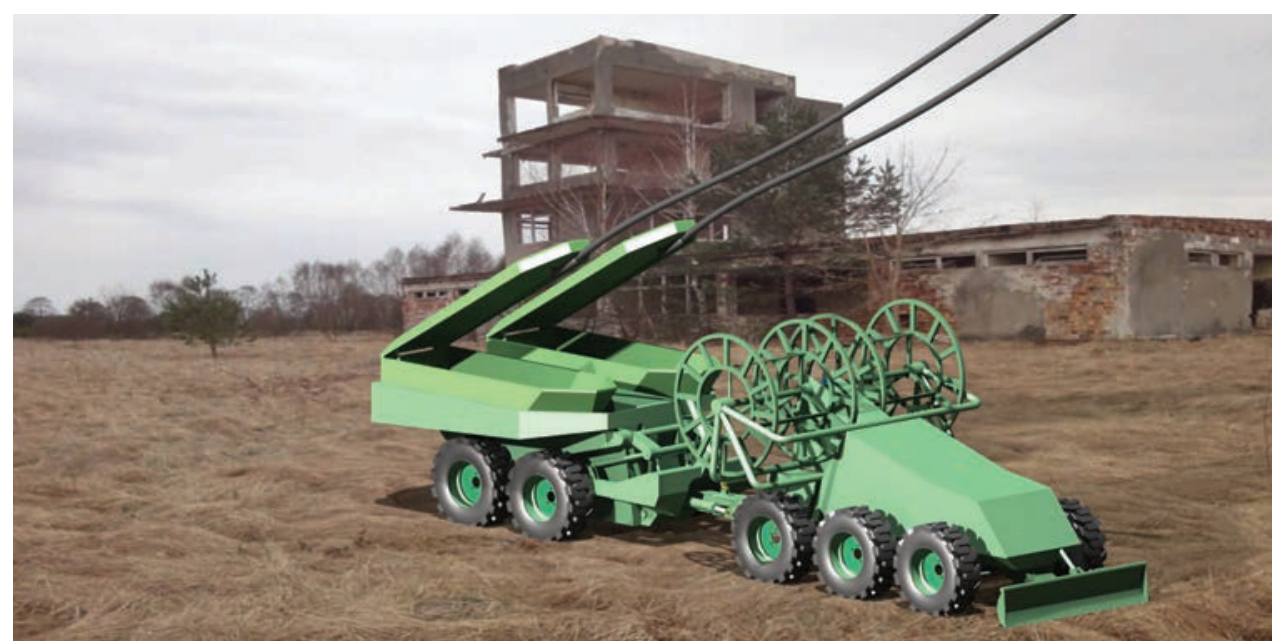

Fig.1. Lengthened devices require a robot with a maximum total weight of 7-8 thousand. $\mathrm{Kg}$ (concept)

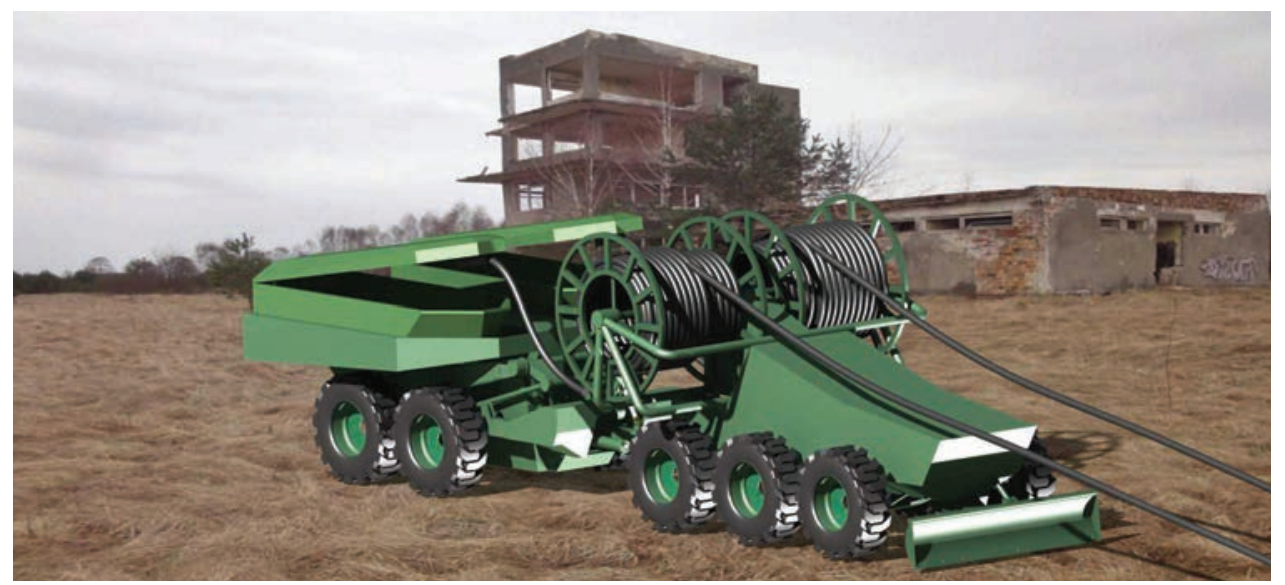

Fig.2. The robot can ensure the removal of traces of the long-term load (concept) that are dangerous for the movement of tracked vehicles

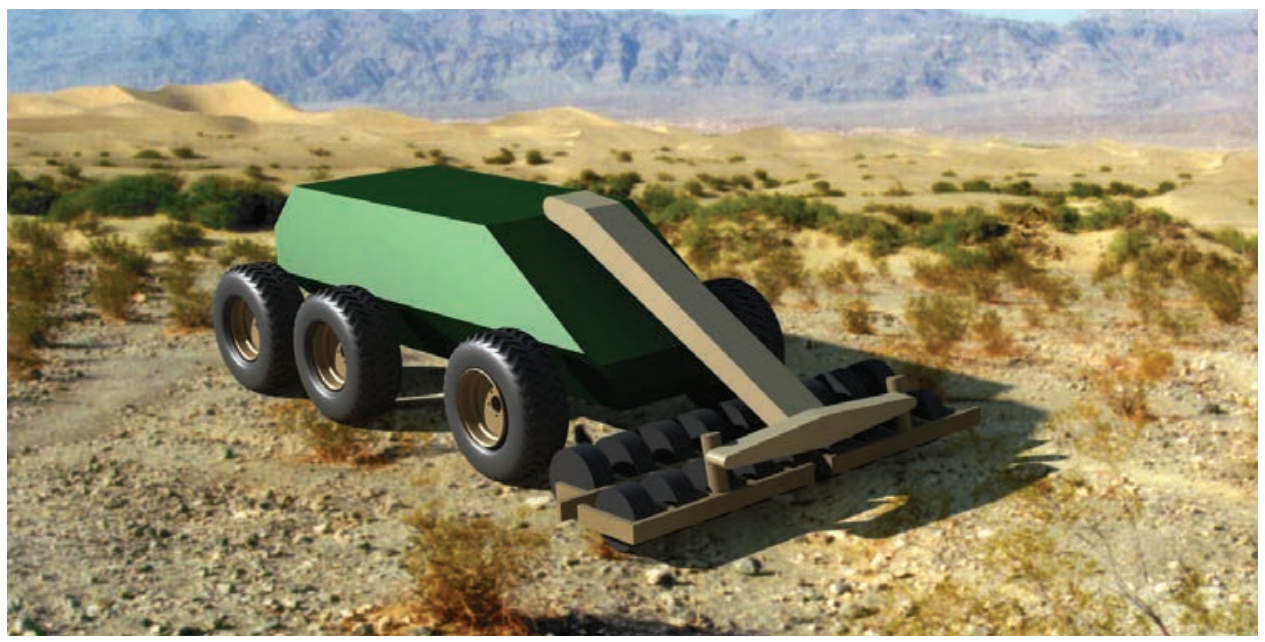

Fig. 3. Remote controlled pressure concept (concept) with hydropneumatics suspension can plow the entire width of the transition at a speed exceeding $10 \mathrm{~km} / \mathrm{h}$ 
Another task after the detonation of the lengthened devices is to expand the passage using the plow. Due to the high speed of trawling and high efficiency of work on different substrates and leaving intact the structure of the ground, a popular solution is the use of pressure plows.

Classical pressure plows are usually rutted trawls and do not traverse the entire width of the passage. They are pushed by heavy, armored tracked vehicles with a large amount of tractive power, hence their weight, rolling resistance and rolling resistance are of no great importance. The length of plowed sections does not usually exceed several hundred meters, and the speed of travel does not exceed 8-10 km / h.

Modern pressure trash with pneumatic tires, hydropneumatics suspension and pneumatic wheels are characterized by significantly lower rolling resistance and steering, and thus do not set too high requirements for tractors (pushers). Hence, lighter tractors with smaller working resistances can plow the entire width of the lane at higher speeds. Under favorable conditions on smooth surfaces can plow even at a speed of $20-30 \mathrm{~km} / \mathrm{h}$.

The effectiveness of plowing at speeds exceeding $8-10 \mathrm{~km} / \mathrm{h}$ depends primarily on the plowing system used. It should ensure an even distribution of pressure on all wheels, despite significant longitudinal and lateral irregularities and prevent dynamic displacement of the wheels from the ground and bouncing of the trawl under the influence of the excursions of kinematic inequalities. In this respect hydropneumatics suspensions cooperating with pneumatic wheels placed in 2 rows are the most effective for fully covering the width of the trawling lane (Fig. 3). Such systems, with a plowing width of $4.5 \mathrm{~m}$, are characterized by a weight of the order of $5000 \mathrm{~kg}$ and low rolling resistance at the level of 0.03-0.1 of gravity depending on the type of the trawl substrate. Taking into account the resistances of elevation in the path (inclinations up to 150), these total resistances of movement may reach 0.3-0.4 of the gravity force. This requires the use of tractors (pushers) with a weight of $10,000 \mathrm{~kg}$. The minimal weight of the plow is therefore at the level of 15 thousand. $\mathrm{kg}$ and is 3-4 times smaller than the weight of manned plowing vehicles. Such a solution ensures full width of trawling and high rate of transition without the need to expose the crew.

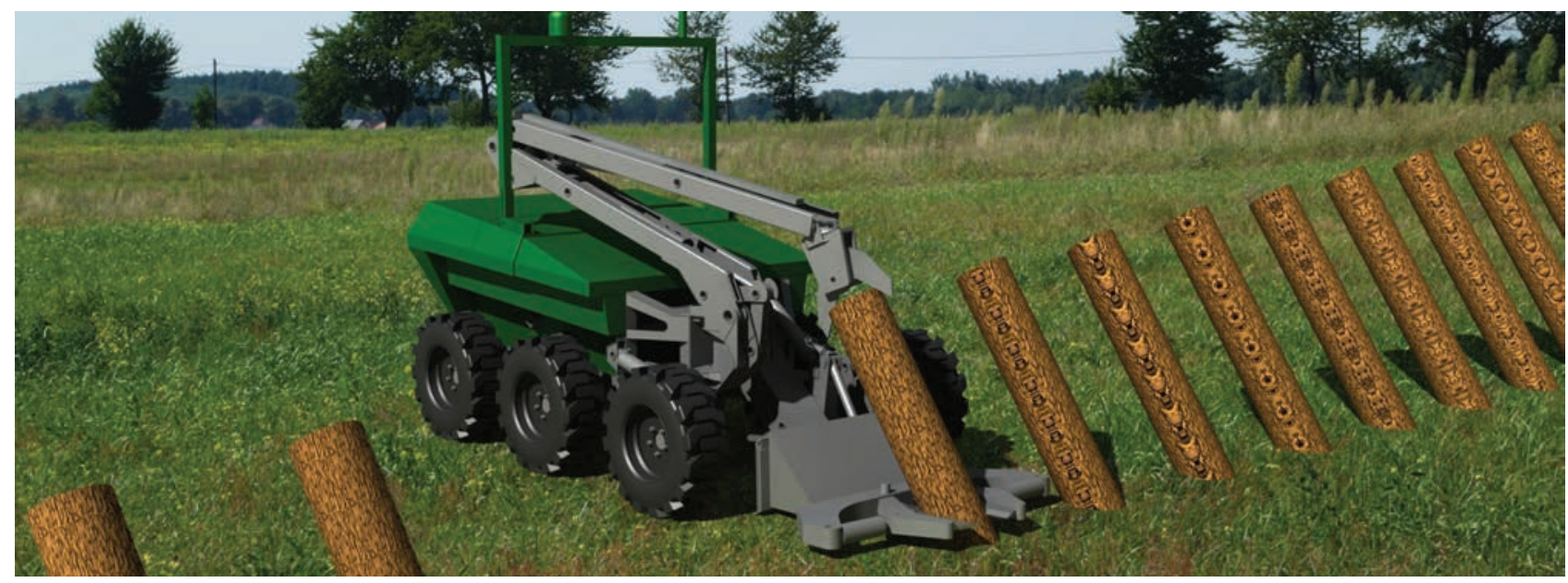

Fig. 4. Cutting the palisades requires a scythe carried by robots of the order of 3 thousand. $\mathrm{kg}$ (concept)

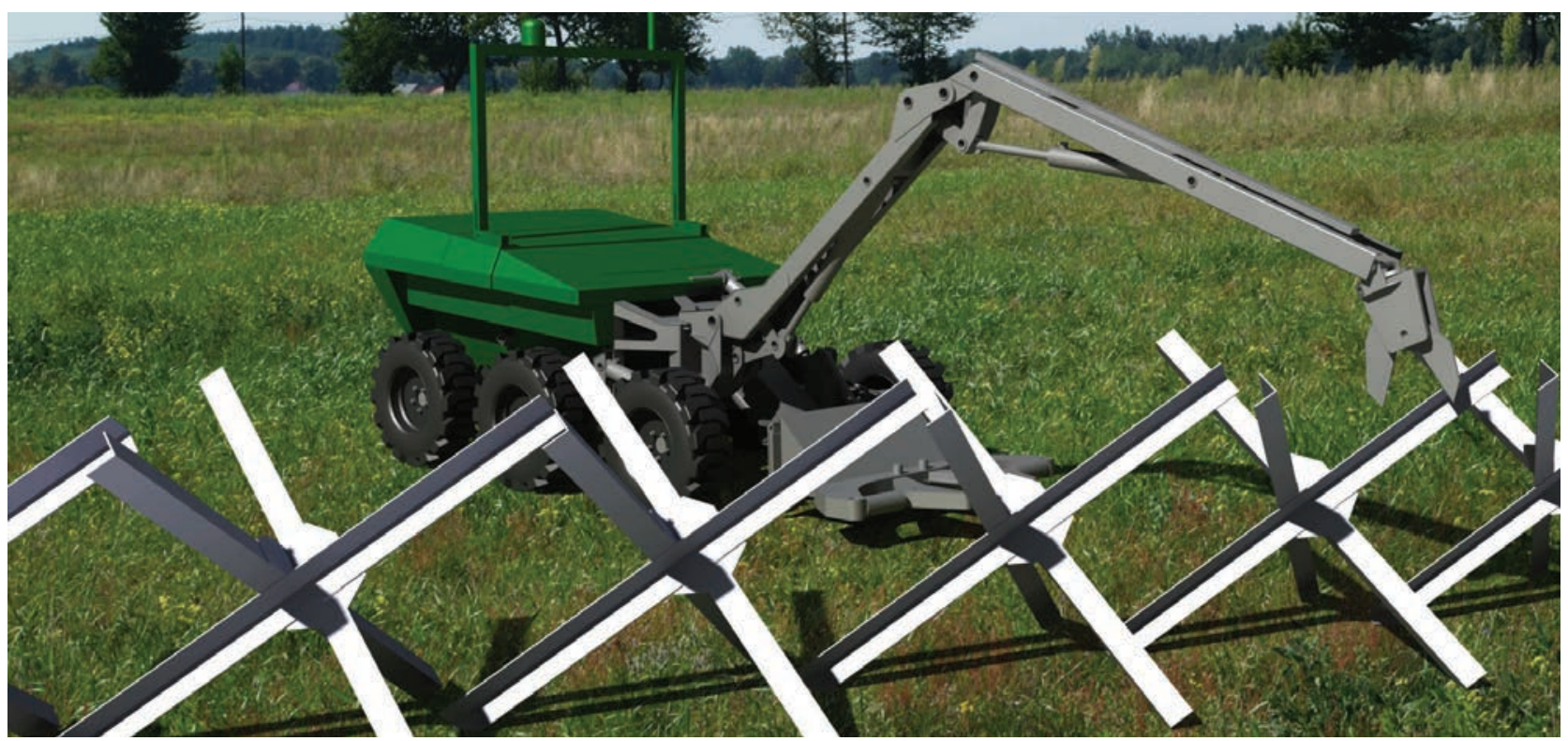

Fig.5. Destroying steel dams does not require the use of very heavy robots (concept) 
Transitions in wire barriers, beam post obstacles and steel dams can be carried out using robots with a weight of 3-4 thousand kg using commercial tools with hydraulic drive available on the market - Fig.4 and Fig.5. These tools are now standard equipment for skid-steer loaders and mini-excavators and their range enables the implementation of diverse tasks without the need to engage in very heavy equipment.

Moving spans with a span of approx. $8 \mathrm{~m}$ and load capacity of the order MLC 70 also does not require the use of heavy equipment (Figs. 6-8), because the mass of the span is at the level of 3 thousand. kg. Depending on the adopted spanning system, the necessary weight of the robot to ensure an adequate level of stability and mobility is at the level of 4-6 thousand $\mathrm{kg}$.

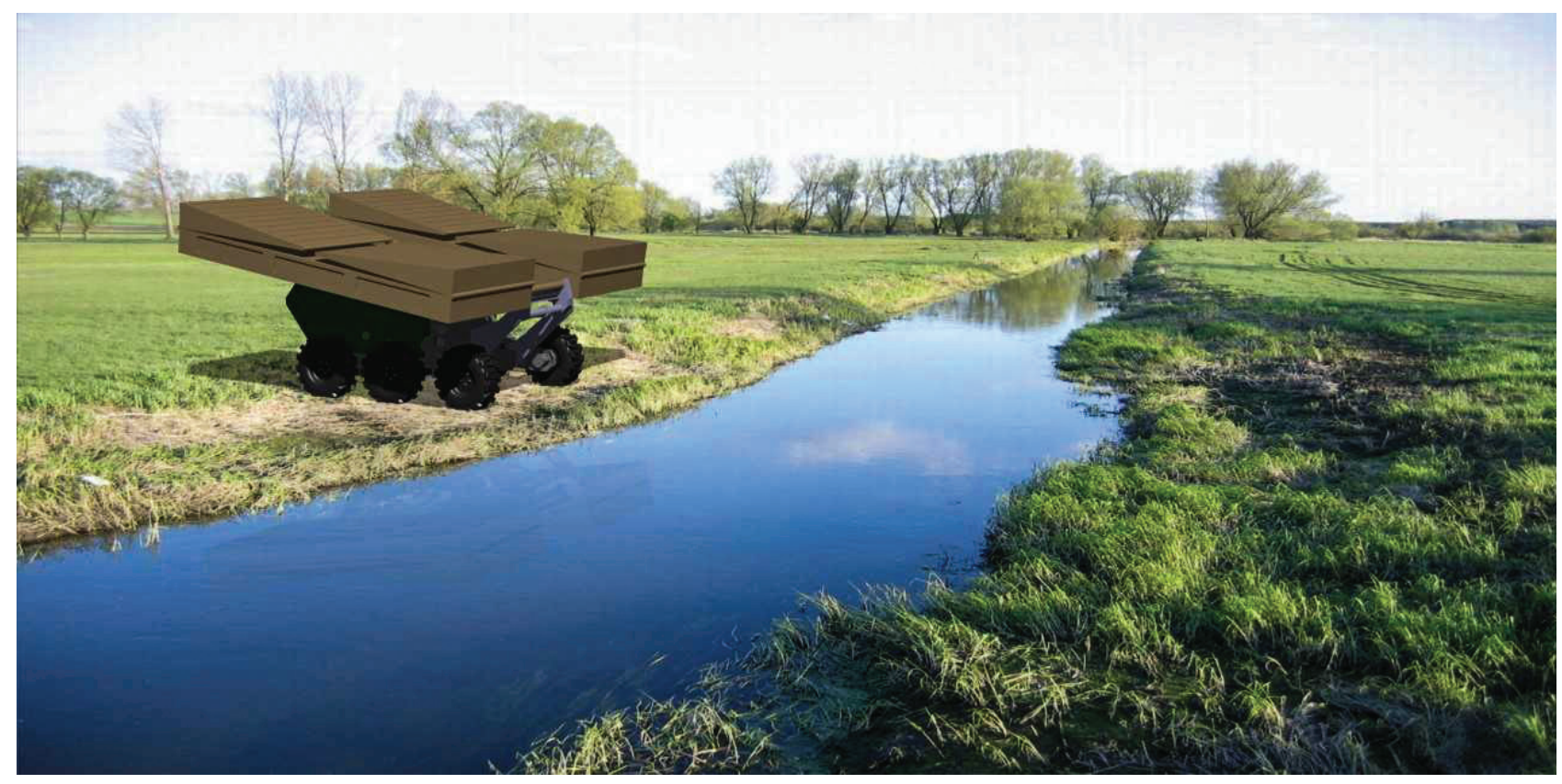

Fig. 6. A robotic bridge to overcome narrow obstacles - span in the transport position (concept)

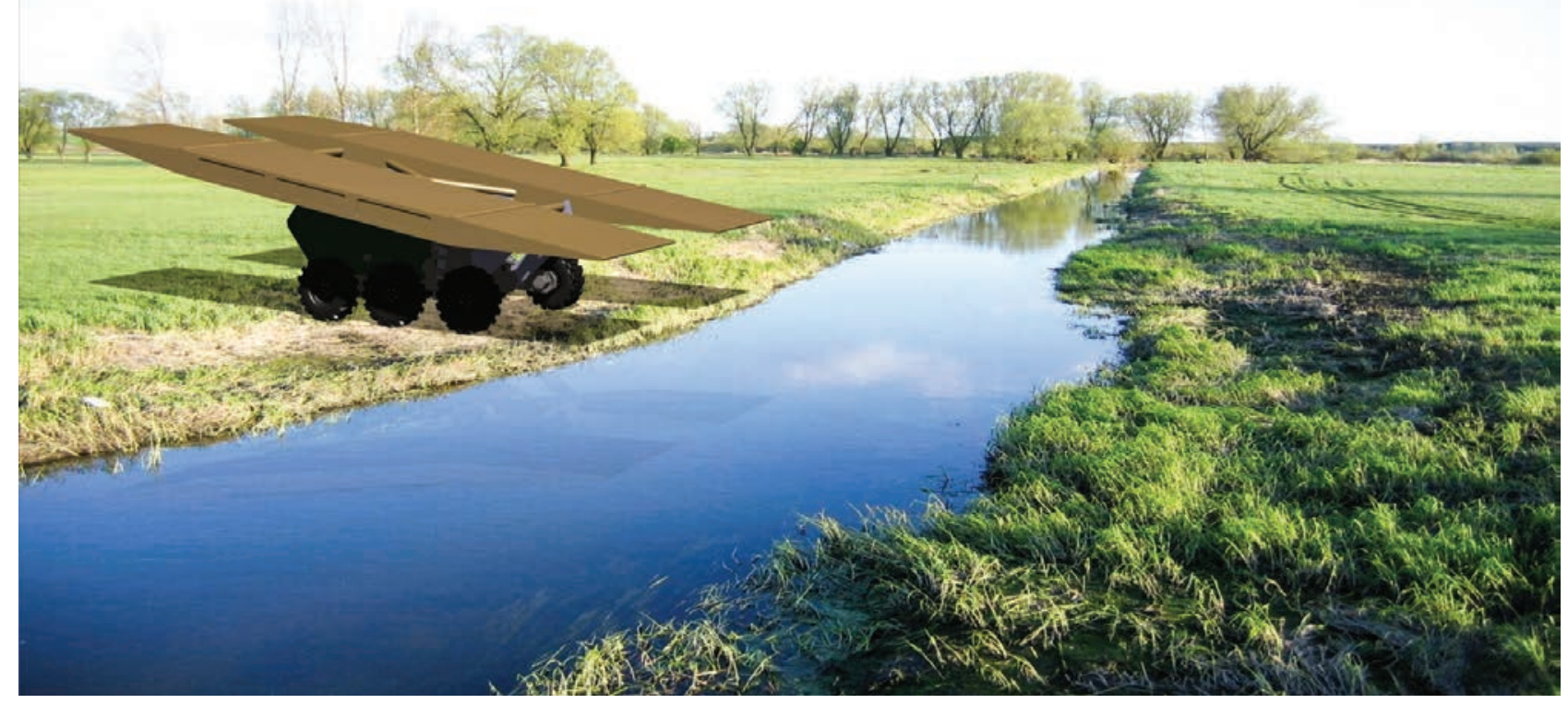

Fig. 7. A robotic bridge to overcome narrow obstacles - span prepared for placing on the obstacle (concept) 


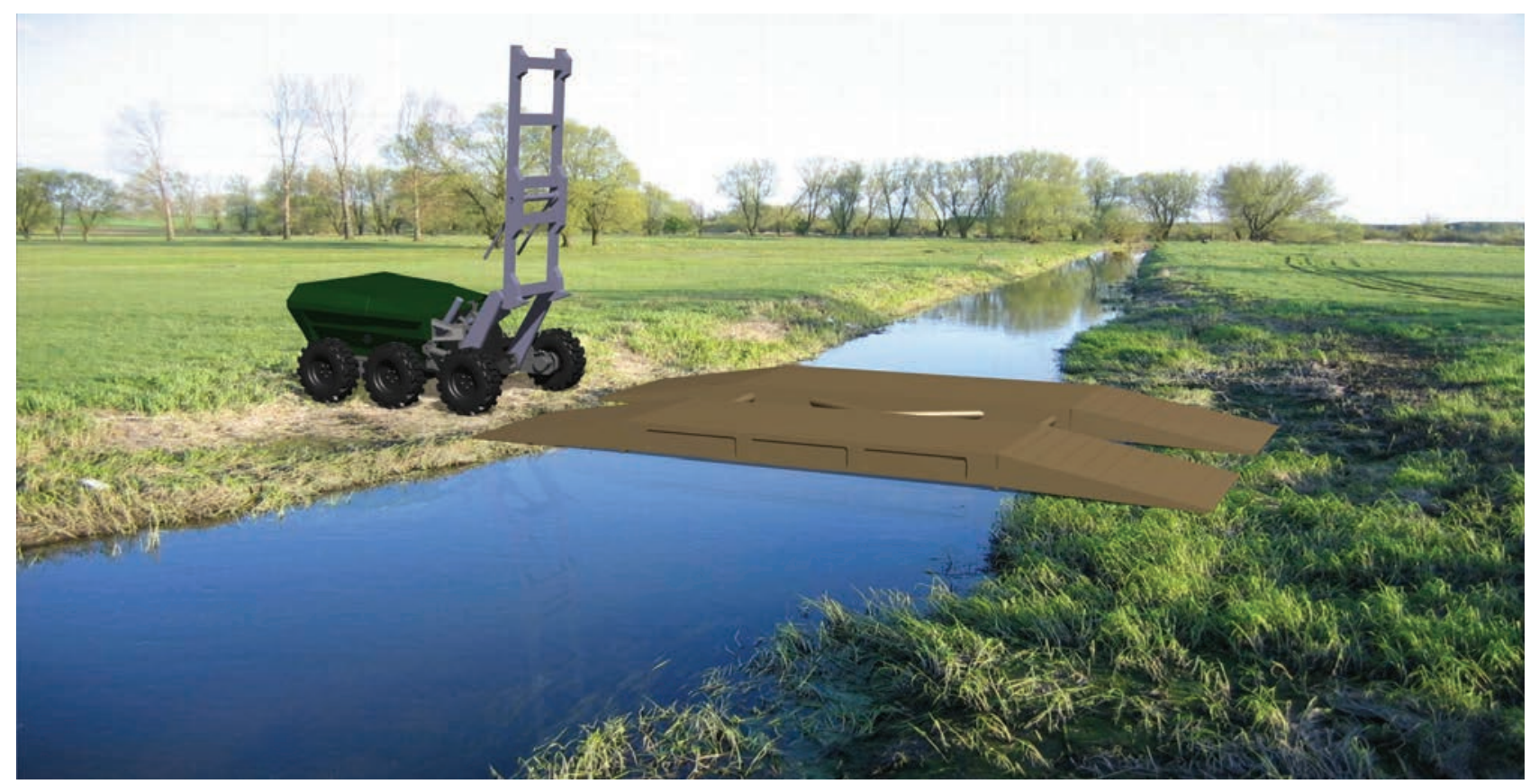

Fig.8. A robotic bridge to overcome narrow obstacles - span after placing on the obstacle (concept)

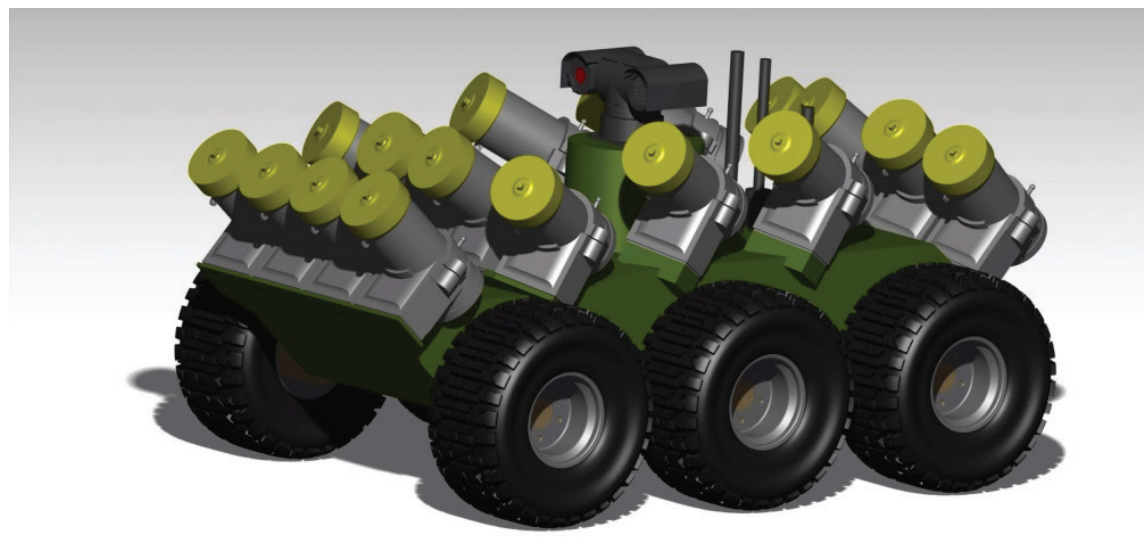

Fig.9. Light, small and fast high mobility robots are able to effectively support masking activities and destroy fortifications and barriers (concept)

The task of destroying defenses, damming up the dams, can successfully carry out light high mobility robots - Fig.9 - with an unladen weight of about $150-200 \mathrm{~kg}$ and a load capacity of 80-100 kg and medium robots with a capacity of approx. $300 \mathrm{~kg}$ and own weight of $600-800 \mathrm{~kg}$. They can also be used to mask activities by transferring grenades and smoke systems and destroying wire barriers and fences. Medium-sized robots are better suited for these tasks because they can be equipped with a larger assortment of tools and attachments and have considerable lifting and pulling forces. With high mobility, low magnetic signature and low pressure on the ground, they should easily penetrate enemy minefields, destroy firewalls with explosive devices and put smokescreens.

A grouping of robots to carry out the passages in engineering dams can therefore consist of relatively light robots including (Fig.10):

- robots - carriers of Bgalore torpedoes;

- pressures plowing robots;

- robots for fencing works;

- robots - carriers of bridge spans;

- robots for destruction and masking.

If necessary, they can be supported by heavy, robotic earthmoving machines. They are necessary in the case of the necessity of making passes in earth dams, such as shielding shafts and, if necessary, removal of very heavy objects or vehicles that terrace the passage made. Robotization of such machines is not currently a major technical problem, because 


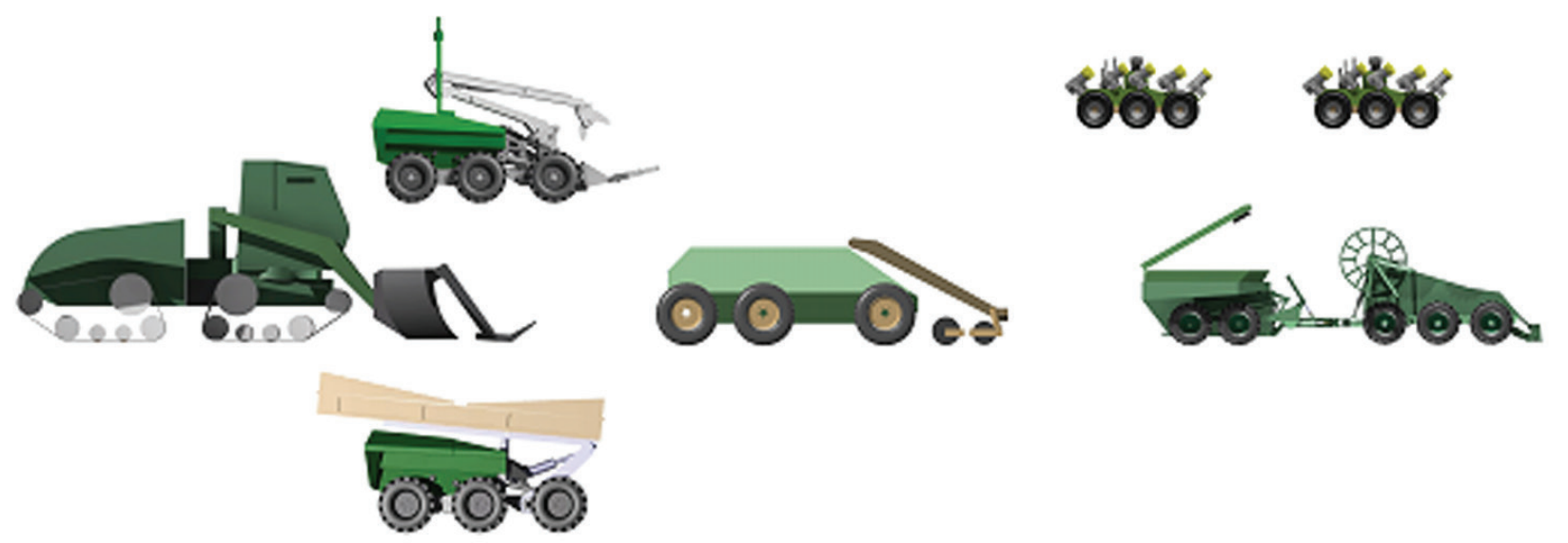

Fig.10. A grouping of robots to perform transitions in engineering dams

most modern machines are currently controlled by electronic information systems that manage both the hydrokinetic drive system as well as the control and hydrostatic drive of work tools. By default, CAN buses are used for this purpose.

\section{Conclusion}

The use of robots to overcome engineering dams has a wide range of development opportunities because they do not impose high demands on the autonomy of operation. In addition, the required coverage does not exceed the capabilities of modern communication systems. To perform the task robotic manned vehicles can be used. However, they are characterized by very large dimensions and masses, which limits their maneuverability. The necessity of moving a few machines along the narrow strip that is removed increases the likelihood of their getting bogged down. They are also not designed for teleoperation. This significantly limits their working possibilities.

Presented concepts and conducted analyzes indicate that eliminating crews (people) from pioneering vehicles allows achieving high efficiency of tasks using much smaller robots. However, this requires searching for new methods and technologies for the implementation of tasks. Complex tasks require the use of teams / groups of cooperating specialized robots and coordination of their activities. Therefore, it is necessary to develop new, more effective teleoperation and telepresence telepresence systems as well as new broadband communications systems, robot control systems and combat situation display systems.

\section{Acknowledgment}

The work presented in this article has been supported by the Polis National Center for Research and Development by grant DOBR -BIO4/083/13431/2013.

\section{References}

1. Allyn Daniel B.: The US Army Robotic and Autonomous System Strategy, US Army Training and Doctrine Command, March 2017.

2. Bogue R.: Detecting mines and IEDs: what are the prospects for robots? The International Journal of Robotics Research and Application. Vol. 38 Issue: 5, pp.456-460

3. IED's, Mines, Route Clearance And Talisman. Think Defence. https://www.thinkdefence.co.uk/2012/07/ieds-minesroute-clearance-and-talisman/

4. Richardson C.: JIEDDO’s Robotics Programs. Military Robitics Summit. 29 August 2012 Washington DC,USA.

5. 5. Robotic and autonomous system strategy. U.S. Army Training and Doctrine Command 950 Jefferson Ave, Fort Eustis, VA 23604 March 2017

6. Rolenec O., Kopuletý M.: Engineer Devices for Obstacle Breaching in Offensive Operations and Possibble Application of Engineer Robots. 2017 International Conference on Military Technologies (ICMT) May 31 - June 2, 2017, Brno, Czech Republic.

7. Unmanned Ground Systems Roadmap. Robotic Systems Joint Project Office,6501 E 11 Mile Rd MS266, Warren, MI, 48397. JUL 2011 